\title{
FORMAÇÃO DOCENTE NO ENSINO FUNDAMENTAL: INTERFACES COM A DIVERSIDADE
}

\author{
Jane Adriana Vasconcelos Pacheco Rios (UNEB)* \\ https://orcid.org/0000-0003-1827-3966 \\ Fabrício Oliveira da Silva (UEFS)** \\ https://orcid.org/0000-0002-7962-7222 \\ Ana Lúcia Gomes da Silva (UNEB)*** \\ https://orcid.org/0000-0002-3880-3322
}

\section{RESUMO}

0 artigo apresenta o perfil socioprofissional de docentes que atuam no Ensino Fundamental, a partir da análise da formação inicial e continuada e suas interfaces com a diversidade. A pesquisa utilizou-se do método Survey, cujos dados foram levantados a partir de um questionário autoaplicável, envolvendo duzentos e oitenta e oito professores(as) de dois municípios baianos. As análises dos dados quantitativos foram realizadas em diálogo com a emergência da diversidade nas políticas de formação de professores(as). 0 estudo evidenciou como a formação inicial, e sobretudo a continuada, são relevantes para o trabalho com a diversidade na profissão docente. Mostrou ainda que os(as) professores(as) investem na formação continuada, realizando-a com vistas a possibilitar progressão na carreira, bem como para desenvolver saberes oriundos de novas aprendizagens em torno das atividades com a temática da diversidade que realizam nas escolas.

Palavras-chave: Formação de professores. Ensino fundamental. Diversidade. Políticas de formação.

\section{ABSTRACT}

\section{TEACHER EDUCATION IN ELEMENTARY SCHOOL: INTERFACES WITH DIVERSITY}

Pós-Doutorado em Educação pela Universidade de São Paulo (USP). Professora Titular Plena da Universidade do Estado da Bahia (UNEB). Professora Pesquisadora do Programa de Pós-Graduação em Educação e Contemporaneidade da Universidade do Estado da Bahia (PPGEDUC/UNEB). Líder do Grupo de Pesquisa Docência, Narrativas e Diversidade na Educação Básica (DIVERSO). E-mail: jhanrios1@yahoo.com.br

** Pós-Doutorando em Educação e Contemporaneidade pela Universidade do Estado da Bahia (UNEB). Professor Adjunto de Didática e Práticas de Ensino do Departamento de Educação da Universidade Estadual de Feira de Santana (UEFS). Professor permanente do Programa de Pós-Graduação em Educação da Universidade Estadual de Feira de Santana (PPGE/UEFS). E-mail: fosilva@uefs.br

*** Pós-Doutorado em Educação pela Universidade Federal do Triângulo Mineiro (UFTM). Professora titular do Departamento de Ciências Humanas da Universidade do Estado da Bahia (UNEB), Campus IV, Jacobina. Docente do Curso de Letras Vernáculas e do Programa de Pós-Graduação em Educação e Diversidade da Universidade do Estado da Bahia (PPED/UNEB) - Jacobina. E-mail: analucias12@gmail.com 
The article presents the socio-professional profile of teachers who work in elementary school, based on the analysis of initial and continuing education and its interfaces with diversity. The research used the Survey method, whose data were collected from a self-administered questionnaire, involving two hundred and eighty-eight teachers from two Bahian municipalities. Quantitative data analyzes were conducted in dialogue with the emergence of diversity in teacher education policies. The study showed how initial and especially continuing education are relevant to working with diversity in the teaching profession. It also showed that teachers invest in continuing education, with the aim to enabling career progression, as well as to develop knowledge from new learning about the activities with the theme of diversity that they perform in schools.

Keyword: Diversity. Teacher education. Elementary education. Training policies.

\section{RESUMEN}

\section{FORMACIÓN DEL PROFESORADO DE ENSEÑANZA PRIMARIA: INTERFACES CON LA DIVERSIDAD}

El artículo presenta el perfil socioprofesional de docentes que trabajan en escuelas de enseñanza primaria, basado en el análisis hechas a respecto de la formación inicial y continua y sus interfaces con la diversidad. La investigación utilizó el método de la Encuesta tipo Survey, cuyos datos se obtuvieron de un cuestionario autoadministrado, en el que participaron doscientos ochenta y ocho docentes de dos municipios bahianos. Los análisis de datos cuantitativos se realizaron en diálogo con la aparición de la diversidad en las políticas de formación docente. El estudio mostró cómo la educación inicial y especialmente la continua son relevantes para trabajar con la diversidad en la profesión docente. También demostró que los maestros y las maestras invierten en educación continua, conduciéndola con el fin de permitir el progreso profesional, así como para desarrollar el conocimiento del nuevo aprendizaje sobre las actividades con el tema de la diversidad que realizan en las escuelas.

Palabra clave: Diversidad. Formación del profesorado. Educación primaria. Políticas de formación.

\section{Introdução}

As discussões sobre a formação de professores(as) têm sido alvo de muitos debates e pesquisas em todo o território nacional. Atualmente, a questão central que envolve a formação passa pela construção do projeto de Educação e, consequentemente, de profissão docente que vem sendo delineado. Os desafios da educação na contemporaneidade são cada vez mais evidentes no cotidiano da Educação Básica, exigindo dos(as) professores(as) uma intensa vigília política, epistemológica, pedagó- gica e formativa para garantir o protagonismo e legitimidade da profissão.

No Brasil, a formação inicial e continuada tem ocupado espaço significativo nas reformas educacionais, principalmente a partir dos anos de 1990, com a Lei de Diretrizes e Bases da Educação Nacional (LDB), Lei no 9.394 (BRASIL, 1996), e das Diretrizes Curriculares Nacionais para a Formação Inicial e Continuada dos Profissionais da Educação Básica, conforme o Parecer CNE/CP no 02, de 9 de junho de 2015 
(BRASIL, 2015), destinadas aos Cursos de Licenciatura; o Plano Nacional de Educação, Lei no 13.005, de 25 de junho de 2014 (BRASIL, 2014)), a Base Nacional Comum Curricular (BRASIL, 2017), entre outras medidas. As políticas de formação docente brasileiras também vinham enfatizando, nas últimas décadas, a inserção dos temas da diversidade nas práticas das redes públicas de Educação Básica, estaduais e municipais, como, por exemplo, a Rede de Educação para a Diversidade instituída pelo Ministério da Educação (MEC), em parceria com a extinta Secretaria de Educação Continuada, Alfabetização, Diversidade (SECAD) ${ }^{1}$ e a coordenação da CAPES para a oferta de cursos semipresenciais de formação continuada e a elaboração de material didático específico.

O Conselho Nacional de Educação (CNE), desde 2011, iniciou discussões a respeito da necessidade de reestruturação dos cursos de licenciatura. 0 resultado de tais reflexões visibilizou-se em 2015, quando foi homologado pelo MEC o Parecer CNE/CP no 02/2015 (BRASIL, 2015), que analisa a situação da formação dos(as) professores(as) no Brasil e do desempenho do sistema educacional. A grande prerrogativa do referido parecer leva em consideração a necessidade, no Brasil, de se pensar, estruturar e desenvolver a formação de professores(as) considerando condições situacionais da educação nacional, a partir dos cotidianos escolares, com vistas a considerar os porquês, o para quê e o para quem é realizada essa formação.

Diante desse cenário, voltamos os nossos interesses para compreender a formação de professores(as) como categoria central de estudo, como foco em discussões que emergem dos modos como o(a) professor(a) habita a profissão docente (RIOS, 2019) na interface com a diversidade. A formação de professores(as) é uma dimensão basilar para entendermos a profissão docente, desenvolvida em condições

1 A SECAD foi reestruturada e substituída pela Secretaria de Educação Continuada, Alfabetização, Diversidade e Inclusão (SECADI), conforme Decreto presidencial noㅜ 7.480, de 16 de maio de 2011 (BRASIL, 2011). diversas na Educação Básica baiana. Analisar os aspectos inerentes à formação significa compreender a relevância e contribuição desta para o desenvolvimento da profissão, tendo em vista os contextos diversos da própria profissão e da atuação de cada professor(a) participante do estudo. Na perspectiva de Nóvoa (2011, 2017), a formação é um elemento matriz que deve constituir-se no seio da própria profissão, sendo produzida em uma "zona de fronteira" entre as universidades e as escolas.

0 estudo que apresentamos neste trabalho é resultado parcial da pesquisa Profissão Docente na Educação Básica da Bahia (RIOS, 2016), ${ }^{2}$ desenvolvida no âmbito do grupo de pesquisa Docência, Narrativas e Diversidade na Educação Básica (DIVERSO), vinculado ao Programa de Pós-Graduação em Educação e contemporaneidade (PPGEduC) da Universidade do Estado da Bahia (UNEB). Trata-se de uma pesquisa quali-quanti que tem por objetivo principal cartografar a profissão docente na Educação Básica do Estado da Bahia, a partir de mapeamento do perfil socioprofissional dos(as) docentes - considerando as dimensões sociodemográfico e cultural, formação, condições de trabalho docente, atuação profissional e participação sindical - e das experiências pedagógicas produzidas na relação com a diversidade. Essa pesquisa elegeu estudar a profissão docente, inicialmente, em dois municípios sede de territórios de identidade, ${ }^{3}$ a saber: Salvador

2 Pesquisa financiada pela Chamada Universal MCTI/CNPq no 28/2018, aprovada pelo Comitê de Ética da UNEB, através do Parecer no 1.231 .920 . O estudo tem parceria com os seguintes grupos de pesquisa: Grupo de Pesquisa Diversidade, Formação, Educação Básica e Discursos (DIFEBA/UNEB); Núcleo Interdisciplinar de Estudos sobre Desigualdades Sociais em Saúde, da Universidade Estadual de Feira de Santana (UEFS); Universidade Observatório de Estudos em Educação, Trabalho e Cultura, da Universidade Federal do vale do São Francisco (/UNIVASF); Grupo de Pesquisa Formação de Professores, Processos e Práticas Pedagógicas, da Universidade do Estado do Rio de Janeiro (UERJ); Grupo de Estudo Docência, Memória e Gênero - História da Educação e Formação de Professores, da Universidade de São Paulo (USP); Grupo de Investigación Memória Docente y Documentación Narrativa, da Universidade de Buenos Aires (UBA).

3 Os territórios de identidade são a atual forma de regionalização do estado da Bahia, a qual foi implementada em 2007 no governo Jacques Wagner (2007-2010), quando 
(Região Metropolitana) e Jacobina (Piemonte da Diamantina).

0 recorte feito neste artigo enfoca aspectos sobre a formação de professores(as) participantes do estudo, discutindo o tipo de formação que realizaram, as contribuições nos processos de profissionalização em diálogo com as políticas de formação voltadas para a diversidade. A pesquisa desenvolvida utilizou, nessa etapa do estudo, um Survey através de um questionário autoaplicável com questões fechadas, disponibilizado aos(às) professores(as) colaboradores(as) da pesquisa, através de um link que permitia o acesso on-line, hospedado na plataforma Survey Monkey. ${ }^{4}$

0 universo da pesquisa é composto por professores(as) concursados(as) do Ensino Fundamental dos municípios baianos de Salvador e Jacobina. Os critérios de seleção desses(as) docentes foram: 1) ser professor(a) efetivo(a) da rede municipal; 2) atuar no ensino fundamental e; c) estar em exercício na escola em sala de aula. A amostra da pesquisa, inicialmente, foi definida por representatividade. Tal amostra foi construída através de um programa de estatística fornecido pelo Núcleo de Pesquisa e Extensão em Saúde (NUDES), parceiro da pesquisa, da Universidade Estadual de Feira de Santana (UEFS). Entretanto, devido ao número de questionários (autoaplicáveis) respondidos, não conseguimos atingir o número de sujeitos estipulado, optando assim pela amostra não probabilística por conveniência. Essa amostra foi composta por 288 professores(as), dos(as) quais 197 pertencem ao município de Salvador e 91 ao município de Jacobina.

Para atendermos aos objetivos anunciados neste artigo, tomaremos, nos tópicos seguintes, a diversidade a partir da análise das políticas de

houve divisão do Estado em territórios de identidade, cuja conceituação de "território" originou-se no Ministério de Desenvolvimento Agrário (MDA), tendo sido adotada pela Secretaria de Planejamento do Estado da Bahia (SEPLAN), inserindo-se os 417 municípios baianos em 27 territórios.

4 Companhia considerada como um "software de serviço" disponível para a realização de pesquisas online, com possibilidades para o desenvolvimento de pesquisa que podem ser personalizáveis ou não. formação e os resultados obtidos na pesquisa desenvolvida com os(as) professores(as) do Ensino Fundamental no âmbito da formação docente na Bahia.

\section{Formação de professores(as) e as políticas da diversidade}

Os processos de escolarização dos(as) professores(as) no Brasil foram delineando a história da própria profissão e seus marcos regulatórios construídos através das diferentes reformas educacionais/políticas de formação instituídas. A formação de professores(as) carrega uma historicidade que demarca contextos sociopolíticos, posições, lutas, negociações, revelando diferentes maneiras de aprender a profissão e, sobretudo, a relacioná-la com os direitos humanos. Inicialmente, podemos situar três marcos legais para a formação do professor no Brasil, sendo: Lei Orgânica do Ensino Normal, Decreto-Lei no 8.530, de 02 de janeiro de 1946 (BRASIL, 1946); a promulgação da Lei no 5.692, de 11 de agosto de 1971 (BRASIL, 1971) - Habilitação Específica para o Magistério; e a chegada dos anos 1990 com a Lei de Diretrizes e Bases da Educação Nacional (BRASIL, 1996), e, nesse período, a emergência de políticas educacionais voltadas para a diversidade. Conforme Gomes (2017a, p. 21):

Ao ser inserida nas políticas, a diversidade faz com que as políticas públicas brasileiras se tornem cada vez mais públicas. Desnaturaliza as formas violentas, preconceituosas e desiguais como têm sido tratados ao longo dos séculos os coletivos sociais diversos. Faz-nos entender que esses coletivos, constituídos por sujeitos sociais e políticos lutam pelo direito à diferença e pelo seu reconhecimento como sujeitos de direitos. Revela a perversa articulação entre desigualdades sociais, raciais e de gênero. Entender a urgência das políticas para a diversidade é compreender que direitos iguais significam a presença dos sujeitos diversos em condições de igualdade nos vários lugares, setores e espaços sociais. As políticas para a diversidade não devem ser vistas como um problema, um incômodo, uma ação de cunho simplesmente partidário 
ou algo que deva ser calado e invisibilizado. Quando reconhecemos a importância dessas políticas no conjunto das políticas públicas, nos colocamos no cerne da luta por direitos e, dentre estes, o direito à diversidade.

Cumpre-nos, incialmente, destacar que vivenciamos no atual cenário mundial e brasileiro a fragilização dos direitos humanos e, consequentemente, a ampliação das desigualdades. Apresentar, pois, a concepção de diversidade a qual nos filiamos é imprescindível, pelo seu caráter polissêmico, cujos sentidos estão sempre em disputa. A diversidade a partir dos estudos do interculturalismo crítico (CANDAU, 2013, 2017; FLEURY, 2002; IVENICKI, 2015, 2018; MCLAREN, 2000; WASH, 2009) requer que a compreendamos a partir de múltiplas dimensão cujos marcadores de gênero, sexualidade, raça, etnia, classe social, entre outras, demarcam as diferenças que provocam tensões que demonstram a necessidade de descolonizar conhecimentos/ formações construídos hierarquicamente. Compreendemos, assim, a diversidade como uma "construção social, histórica, cultural, política e econômica das diferenças que se realiza no contexto das relações de poder" (GOMES, 2017a, p. 15).

Inspirada nas agendas multilaterais internacionais em que a demanda pela equidade virou a tônica de várias conferências internacionais que ocorreram nos anos de 1990, entre elas a conferência Educação para o século XXI, realizada pela UNESCO, instaurou-se a Década da Educação no Brasil legislada pelo Plano Nacional de Educação para Todos (BRASIL, 1993), Lei de Diretrizes e Bases da Educação Nacional (BRASIL, 1996) e os Parâmetros Curriculares Nacionais (BRASIL, 1997) voltados para a universalização da Educação Básica, a inclusão e a diversidade, reestruturando assim os cursos de formação de professores(as) a partir destes princípios. É preciso ressaltar que, nesse período, estes princípios são resultantes das demandas da globalização econômica no contexto de mudanças e regulações neoliberais em que cabe aos/às professores(as) a reorganização dos diferentes grupos sociais presentes nas escolas. A diferença foi tratada como política compensatória.

Entre esses documentos, a LDB ocupou um lugar central no processo de formação inicial e continuada dos(as) professores(as) da Educação Básica. Para atender a este cenário, uma das primeiras exigências foi a formação em nível superior para os(as) docentes, multiplicando os cursos de formação inicial. Além disso, exigiu-se a manutenção de programas de formação continuada em diferentes níveis, assegurando através do Plano Nacional de Educação (BRASIL, 2014) a articulação com as instituições de ensino superior e as secretarias de educação. Nesse cenário, a LDB trouxe a diversidade à cena a partir das modalidades de ensino; entre elas inseriu: educação de jovens e adultos, educação de pessoa com deficiências no ensino regular no atendimento educacional especializado, educação indígena e da população do campo. Segundo Carreira (2017, p. 83),

[...] as modalidades de ensino na LDB constituíram uma 'porta de entrada' de diferenças na educação, com base em uma diferença abordada como direito específico de determinados segmentos da população, marcados pelas desigualdades socias, a uma educação diferenciada

Em relação aos anos 2000, para compreendermos como se caracteriza o cenário das políticas nacionais de formação na interface com a diversidade, mapeamos o conjunto das políticas, considerando como elementos basilares para uma análise panorâmica algumas políticas e programas de formação desenvolvidos pela Secretaria de Educação Continuada, Alfabetização e Diversidade (SECAD). No âmbito do Ministério de Educação, a SECAD, através do Decreto no 5.159, de 28 de julho de 2004 (BRASIL, 2004), teve como desafio construir a nova política nacional de alfabetização e educação de jovens e adultos e a adoção de políticas afirmativas para inclusão e diversidade. A SECAD ficou responsável por políticas e ações referentes à educação escolar 
indígena; educação do campo; educação para as comunidades remanescentes de quilombos; apoio a grupos socialmente desfavorecidos do acesso às universidades; educação para a diversidade étnico-racial e a valorização da história e da cultura afro-brasileiras; educação ambiental; ações educacionais para crianças e adolescentes em situação de risco e vulnerabilidade social; educação em direitos humanos; educação para a população prisional. Diante desse cenário, vários cursos de aperfeiçoamento, especialização e extensão foram ofertados aos/às professores(as), sobretudo com a criação da Rede de Educação para a Diversidade, constituída por um grupo de instituições públicas de ensino superior dedicado à formação continuada a partir da agenda da SECAD em parceria com a Universidade Aberta do Brasil (UAB), criada pelo Decreto no 5.800 , de 8 de junho de 2006 (BRASIL, 2006).

Dentre os marcos históricos na política de formação de professores(as), com ênfase na diversidade, destacamos a Lei $\mathrm{n}^{\circ} 10.639$, de 09 de janeiro de 2003 (BRASIL, 2003), que, através das suas diretrizes, nos permitiu transcender as referências euro-androcêntricas, ainda praticadas nas escolas do país, as quais ratificam um ritual de apagamento da história e cultura do povo negro que fecunda a sociedade brasileira historicamente em âmbitos diversos, dentre eles: cultura, religiosidade, culinária, artes, música, dança, língua mão-de-obra de trabalho etc. É preciso reconhecer, como bem sinaliza Gomes (2017b), que a referida Lei é conquista do Movimento Negro Brasileiro, que, tensionando o neocolonialismo, promoveu mudanças na ação do Estado, e que, consequentemente, reconheceu a sua dívida histórica com a população afrodescendente, ainda vítima da perversidade do racismo e das desigualdades raciais, sociais e de gênero, que rezam na Constituição de 1988 (BRASIL, 1988) e que volta à cena do debate na III Conferência Mundial contra o Racismo, a Discriminação Racial, a Xenofobia e Formas Correlatas de Intolerância (ORGANIZAÇÃO DAS NAÇÕES UNIDAS, 2001), conhecida como Conferência de Durban, na África do Sul, em 2001.

As Diretrizes Curriculares da Educação Básica (BRASIL, 2010), em 2010, instituíram a modalidade da educação escolar quilombola, tendo como base a LDB, no que se refere ao reconhecimento da diversidade, e o Plano Nacional de Implementação da Lei no 10.639/2003, que prevê a garantia de uma educação quilombola diferenciada. Em relação à educação escolar indígena, foram implementadas ações voltadas para a formação inicial em Licenciaturas Interculturais Indígenas, criada no marco do Programa Diversidade na Universidade. Em 2008, também foram implementadas ações para formação dos profissionais que atuam com Educação de Jovens e Adultos no Sistema Prisional, através do Projeto Educando para a Liberdade, vinculado ao Plano de Desenvolvimento da Educação por meio do Plano de Ação Articulada Prisional. A educação ambiental fez parte da agenda da SECAD/SECADI por meio de formação continuada de professores(as) e elaboração de proposta de um Subsistema Nacional de Educação Ambiental. Em relação à inclusão escolar, as questões voltadas para a formação ganharam força no debate educacional nos anos 2000, compondo o texto da Política Nacional de Educação Especial (CARREIRA, 2017).

Quanto à Educação do Campo, as políticas de formação nascem com o Programa Nacional de Educação na Reforma Agrária (Pronera) (BRASIL, 1998); em seguida as Diretrizes Operacionais para a Educação do Campo (BRASIL, 2002) instituem propostas de formação de professores(as) voltadas para o campo e o Programa de Apoio à Formação Superior em Licenciatura em Educação do Campo (BRASIL, 2007), a fim de promover a formação de professores(as), por área de conhecimento, para atuarem junto às escolas do campo na educação básica. E, por fim, o Programa Nacional de Educação do Campo (BRASIL, 2013), que teve como objetivo garantir a formação de professores(as), produção de material didático, acesso 
e qualidade na educação no campo em todas as etapas e modalidades.

Outro aspecto importante a ser considerado nas políticas de formação para a diversidade é a questão de gênero. As políticas de formação de professores(as) voltadas para esse aspecto fizeram parte do Projeto Escola sem Homofobia. O programa surgiu como uma das ações para promover debates políticos acerca da garantia dos direitos humanos e da respeitabilidade das orientações sexuais e identidade de gênero no âmbito escolar. Deste programa nasceu o kit anti-homofobia ${ }^{5}$ que, por pressão política, foi vetado pela Presidência da República, em maio de 2011. Conforme nos diz Deslandes (2015, p. 87):

A recepção do termo gênero com suas derivações pós-estruturalistas que ampliam o conceito para o universo das 'múltiplas identidades' levou a um forte acirramento das tensões políticas e à instituição de um verdadeiro campo de batalhas, inclusive entre os poderes executivo e legislativo do Estado que, grosso modo, acabou por acarretar na supressão, total ou parcial, das políticas educacionais voltadas para a construção de uma escola da igualdade de gênero no Brasil para o decênio 2015-2025.

O cenário político atual vai de encontro ao pluralismo de ideias e à liberdade de pensamento. Neste contexto, as políticas da diversidade vêm sendo ameaçadas dentro da sala de aula através de um Projeto de Lei proposto pelo Senador Magno Malta que inclui, entre as diretrizes e bases da educação nacional de que trata a Lei no 9.394, de 20 de dezembro de 1996 (BRASIL, 1996), o Programa Escola sem Partido, ao destacar a crença aos costumes, religião, sem impor pontos de vistas, como direitos dos pais, mães e dos(as) estudantes. Entretanto, percebemos que a real proposta desse projeto de lei é o silen-

50 material pedagógico foi elaborado sob supervisão da SECAD/SECADI, em parceria com a rede internacional Global Alliance for LGBT Educacion (GALE) e a Associação Brasileira de Lésbicas, Gays, Bissexuais, Travestis e Transexuais (ABGLT). Este material ficou conhecido por "kit gay" através dos opositores políticos e religiosos à sua implementação nas escolas públicas. ciamento das minorias na perspectiva de não discutir, no ambiente escolar, conteúdos que oportunizem a criticidade, o pluralismo de ideias, a diversidade, qualquer que seja sua dimensão. Além disso, nos cumpre reiterar que este projeto fere os itens II e III do art. 208 da Constituição Federal (BRASIL, 1988), pois estes conteúdos são de suma importância para discussão e manutenção de valores/ ideias necessárias à construção de ponto de vista crítico-reflexivo da formação integral do sujeito.

Nesse sentido, as consequências são assustadoras para a prática pedagógica do(a) professor(a), haja vista que a liberdade é cerceada, visando a realização da prática pedagógica neutra, acrítica, correndo risco de ser criminalizada ao se posicionar, defender, argumentar acerca de filiações teóricas e concepções que estão de acordo com o princípio de liberdade de expressão e de cátedra, conforme preza a Constituição Federal.

Ainda que tenhamos vivido importantes avanços em relação às políticas de formação voltadas para a diversidade, não foi possível implementar políticas educacionais de fortalecimento e continuidade que pudessem demarcar um lugar político na agenda nacional em prol das desigualdades acirradas nesse país, acarretando supressão ou substituição total de muitas das ações construídas ao longo de todo este período. De acordo com Gomes (2017a, p. 14):

0 grande desafio e que ainda não foi concluído é que os sujeitos dessas políticas pudessem ser não somente os seus destinatários, mas, principalmente, sujeitos na construção da agenda e na formulação dessas mesmas políticas. Ainda nos falta institucionalizar políticas para a diversidade que sejam construídas com os sujeitos diversos e não somente para os sujeitos diversos. E isso só poderá ser alcançado com uma intensa participação social.

Diante das políticas de formação implementadas no país nas duas últimas décadas, apresentaremos a seguir o que revelaram os(as) docentes da pesquisa Profissão Docente na 
Educação Básica da Bahia acerca da formação inicial e continuada e suas interfaces com a diversidade.

\section{0 que revelam os(as) professores(as) sobre a formação inicial?}

A pesquisa realizada mostrou que a formação inicial e continuada são dimensões fundamentais para a constituição da profissão docente. É nesse espaço que as questões articuladas à diversidade são trazidas pelos(as) docentes através de inserções e silenciamentos na construção da carreira.

Neste trabalho analisamos a dimensão da formação docente na construção do perfil socioprofissional que nos possibilitou levantar as seguintes informações: nível de escolarização, formação inicial, cursos de pós-graduação, formação continuada, contribuições da formação na atuação docente e a relação da formação com as questões da diversidade. Os dados obtidos procuram situar a formação docente na constituição da profissão docente e, sobretudo, suas interfaces com as políticas educacionais voltadas para a diversidade.

$\mathrm{Na}$ pesquisa realizada, a maioria dos(as) professores(as) são oriundos(as) do Curso de Magistério, sendo 50,68\% dos(as) docentes de Salvador e 70,18\% de Jacobina, enquanto $40,4 \% \operatorname{dos}$ (as) docentes realizaram formação geral e/ou técnica. Isto torna-se mais evidente no município de Salvador, com um total de $46,6 \%$ dos(as) respondentes. No que se refere à formação inicial, o que podemos perceber é que $100 \%$ dos(as) docentes respondentes de Salvador e 98,2\% dos de Jacobina possuem nível superior. Destes, 96\% fizeram licenciatura.

A predominância da opção pela Licenciatura pode coadunar-se com o atendimento aos objetivos dos Planos Nacionais de Educação (2001 e 2014), nos quais se prevê a exigência da formação em nível superior para atuação de professores(as) na Educação Básica. Vale ressaltar que, apesar de à época da promulgação da LDB, Lei no 9.294/96 (BRASIL, 1996), não haver obrigatoriedade para habilitação de professores(as) em curso de nível superior para a educação infantil e séries iniciais do Ensino Fundamental, permitindo a inserção nestas etapas do ensino com o nível médio na modalidade normal, ${ }^{6}$ consolidou-se na Prefeitura Municipal de Salvador, de acordo com a Lei complementar no 34, de 09 de junho de 2003 (SALVADOR, 2003), a contratação tanto em nível de concurso público como em processo seletivo simplificado a exigência em editais do nível superior em Licenciaturas para o exercício do magistério, tais como previstos nos editais de concurso para professores(as) efetivos(as) no 02/2003 e no 01/2010.

Dos cursos de Licenciatura realizados pelos(as) docentes envolvidos(as) com a pesquisa, o que prevaleceu foi a formação em Ciências Humanas, distribuídos da maneira indicada no Gráfico 1.

Podemos perceber que, em Jacobina, o curso predominante realizado pelos(as) docentes é Letras, diferentemente de Salvador, que é Pedagogia. Isto se justifica pela oferta de cursos nos municípios, sobretudo em Jacobina, em que a única Instituição de Ensino Superior (IES) pública é a Universidade do Estado da Bahia (UNEB), que oferece os cursos de Licenciatura em Letras, Letras - Inglês e Literaturas, História, Geografia e Educação Física.

Os dados apontam que a formação inicial da maioria dos(as) respondentes aconteceu em IES pública, totalizando 59,5\% dos(as) professores(as). No município de Jacobina, 71,7\% dos(as) docentes fizeram a graduação em instituições de ensino superior pública e 21,7\%, em instituições privadas. Destes, 28,3\% realizaram a primeira graduação de modo presencial, 8,7\% em cursos a distância e 10,9\% afirmaram que

6 Em 2014, o Plano Nacional da Educação (PNE), Lei no 13.005, de 25 de junho de 2014, estabeleceu, em sua Meta 15 que "todos os professores e as professoras da educação básica possuam formação específica de nível superior, obtida em curso de licenciatura na área de conhecimento em que atuam" (BRASIL, 2014) 
o curso foi regular. Observa-se aqui a presença de cursos de formação realizados através do Plano Nacional de Formação de Professores da
Educação Básica (PARFOR), ${ }^{7}$ atendendo a um percentual de 2,2\%, aspecto não identificado no município de Salvador.

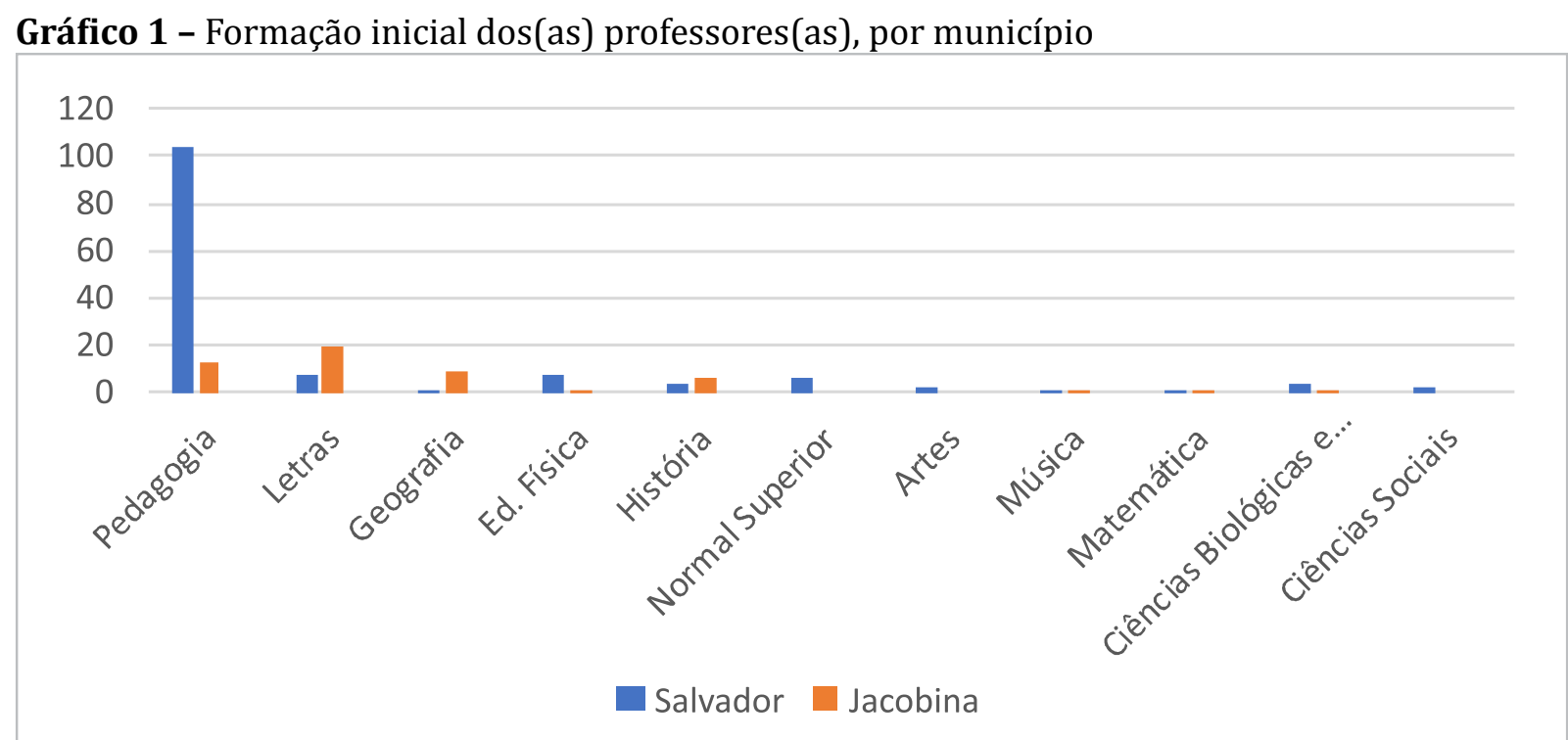

Fonte: Survey (2017).

Os(as) professores(as) revelaram que a formação implica diretamente no desenvolvimento da profissão docente, sendo que 51,7\% avaliam como excelente a contribuição da formação inicial para a prática profissional. A validação da formação como relevante para a atuação profissional é um indicativo de que os(as) professores(as) reconhecem o lugar da reflexão e da construção de modos colaborativos que são produzidos no contexto da própria profissão como forma de desenvolver-se profissionalmente, corroborando com o que afirma Nóvoa (2011) sobre o papel da formação na relação entre Universidade e Escola. Nesta direção, a formação não significa apenas um modo de construir caminhos para o(a) professor(a) exercer a profissão, mas vai além disso, pois é o modo como essa profissão se constitui a partir da base reflexiva que demanda construção epistêmica da docência produzida com o outro no ambiente educativo.

No que se refere às questões da diversidade, 39,5\% dos(as) docentes apontam que estas discussões apareceram na formação inicial voltadas para a pesquisa. A diversidade vai configurando-se no cenário da formação inicial destes(as) docentes como elemento que inspira/fundamenta investimentos na pesquisa. Neste sentido, a formação inicial de professores(as), nas últimas décadas, vinha promovendo discussões e formações em que a diversidade estava presente nos cursos de licenciatura, fato que nos possibilita entender que $39,5 \%$ afirmam que as discussões sobre a diversidade aconteciam nas formações iniciais.

O período em que estes(as) professores(as) efetivaram sua formação inicial culmina com a emergência de políticas públicas de formação para a diversidade na educação, a partir da criação da Secretaria de Educação Continuada, Alfabetização e Diversidade (SECAD), no âmbito do Ministério de Educação. A relação com a formação instituída através da SECAD/ SECADI ficará mais evidente na análise dos dados sobre a formação continuada apresentados a seguir.

7 A Política Nacional de Formação de Professores da Educação Básica foi instituída através do Decreto $\mathrm{n}$ 6.755, de 29 de janeiro de 2009 (BRASIL, 2009a), e o Plano Nacional de Formação de Professores da Educação Básica (PARFOR), pela Portaria no 9, de 30 de junho de 2009 (BRASIL, 2009b), por intermédio da Coordenação de Aperfeiçoamento de Pessoal de Nível Superior (CAPES). 


\section{Formação continuada e as interfaces com a diversidade}

Ao tratar da formação docente, consideramos aqui que o(a) professor(a) constrói processos contínuos de formação que são delineados a partir da sua formação inicial e continuada.
A continuidade da formação dos(as) professores(as) acontece de duas maneiras. A primeira é por meio da ampliação da titularidade, com a busca pelos Cursos de Pós-Graduação. No caso específico dos(as) professores(as) de Salvador e Jacobina, a formação acadêmica possui a configuração apresentada na Tabela 1 .

Tabela 1 - Professores(as) com Pós-Graduação por tipo de titulação

\begin{tabular}{|c|c|c|c|c|}
\hline \multirow{2}{*}{ Titulação } & \multicolumn{2}{|c|}{ Salvador } & \multicolumn{2}{c|}{ Jacobina } \\
\cline { 2 - 5 } & Quant. & $\%$ & Quant. & $\%$ \\
\hline Graduação & 148 & 100 & 56 & 98,2 \\
\hline Especialização & 124 & 83,7 & 40 & 70,1 \\
\hline Mestrado & 25 & 16,8 & 5 & 8,7 \\
\hline Doutorado & 5 & 3,37 & 0 & 0 \\
\hline
\end{tabular}

Fonte: Survey (2017).

A busca pela continuidade dos estudos apresenta-se de forma isolada, solitária, sem um incentivo específico para isto nas redes de ensino. As políticas de incentivo e de afastamento dos(as) docentes para cursar mestrado ainda não são uma realidade entre os(as) respondentes. Alguns(mas) docentes fazem o curso trabalhando, mas com poucas condições de sucesso. Muitos(as) professores(as) nem tentam fazer um mestrado, pois são consumidos(as) pela atividade laboral na docência e pela pouca condição de realização no seu próprio município. Ao olharmos para os dados de Salvador, percebemos que o número de docentes com mestrado, que somam 25 professores(as), ainda é maior que em Jacobina, que conta apenas com 05 professores(as) com esse tipo de formação. Isso se deve à baixa oferta do curso de mestrado no interior. Em Jacobina há apenas um Programa de Mestrado Profissional em Educação e Diversidade (MPED), da Universidade do Estado da Bahia (UNEB).

Com o processo de interiorização e de expansão dos mestrados, inclusive mestrados profissionais, há uma tendência a elevar o número de professores(as) da Educação Básica inseridos(as) nesse tipo de pós-graduação.
Acreditamos que os mestrados profissionais com foco na diversidade poderão subsidiar os processos formativos dos(as) professores(as), possibilitando a estes o trabalho com a diversidade numa perspectiva que favoreça $o$ desenvolvimento de práticas educativas voltadas para uma construção de saberes fincados em abordagens interculturais. Assim como a formação continuada também pode tornar-se um vetor para que se considere a diversidade como eixo central da formação intercultural de professores(as).

No que tange a pós-graduação lato sensu, fica evidenciado que, hegemonicamente, ocorre em instituições privadas. Conforme apontam os dados, em Salvador, 69\% dos cursos de especialização são feitos em instituições privadas e $21 \%$ em instituições públicas. Em Jacobina, $72,2 \%$ dos cursos foram feitos em instituições privadas e $22,2 \%$ em instituições públicas. Esse quadro pode ser influenciado pela pouca oferta de cursos na rede pública nas cidades de Salvador e Jacobina. A Universidade do Estado da Bahia oferta, na cidade de Salvador, apenas 3 cursos presenciais e 3 na modalidade a distância ou semipresencial ligados à área de educação. Em Jacobina, a UNEB oferta apenas 
1 curso presencial, que não está diretamente ligado à área de educação ou ensino. Segundo Freitas (2012, p. 123):

A não valorização, pela CAPES, dos cursos de especialização como curso de pós-graduação lato sensu, vinculados aos programas de pósgraduação stricto sensu, leva-nos a afirmar que a inexistência dos cursos de especialização na imensa maioria das universidades públicas tem direcionado os professores para cursos de especialização em instituições privadas, que, por sua vez, criaram um nicho mercadológico próprio para atender uma demanda das redes e dos docente na busca pela titulação como única forma de ascensão na carreira

A fim de compreender como se configura o cenário de formação continuada dos(as) professores(as) participantes da pesquisa, buscamos saber se nos últimos dois anos participaram de atividades de formação, tais como: cursos de aperfeiçoamento docente, atividades promovidas pela escola, atividade promovidas pela secretaria de educação, eventos e cursos sobre educação com investimento próprio, entre outros. Essa foi uma questão que permitiu que o(a) docente marcasse mais de uma possibilidade, caso tivesse realizado dois ou mais cursos.

O percentual de professores(as) de Salvador que participa de curso de aperfeiçoamento chegou a $55 \%$, o que revela que o(a) professor(a) ainda busca os cursos de aperfeiçoamento como forma de melhorar sua prática, mas também, e principalmente, para progredir na carreira. Tanto em Salvador como em Jacobina os(as) docentes são promovidos por realização de cursos de aperfeiçoamento. Acreditamos que uma das explicações para esse percentual seja o fato de que poucos(as) professores(as) acessam os cursos de pós-graduação, sobretudo mestrado e doutorado, e, portanto, investem nos cursos de aperfeiçoamento como forma de garantir condições de melhoria da condição de atuação profissional, bem como em razão da possibilidade de progressão na carreira. Em Jacobina a situação não é diferente, pois 55\% dos(as) professores(as) afirmam terem feito algum curso de aperfeiçoamento nos últimos dois anos.
No que se refere às atividades promovidas pela própria escola, em Salvador, 40\% dos(as) professores(as) afirmam ter participado de alguma atividade de formação desenvolvida na própria escola. Em Jacobina o número é um pouco maior, perfazendo $47 \%$ das respostas. Isso indica que há uma incidência grande de professores(as) em atividades de formação realizadas na própria escola. Ao analisar os dados de Salvador, observamos que as atividades de formação desenvolvidas na escola chegam a $20 \%$, percentual igual às atividades de formação desenvolvidas pela Secretaria Municipal da Educação (SEMED). Em eventos custeados pelo próprio(a) professor(a), o percentual é de 18\%, e nos cursos de aperfeiçoamento o percentual chegou a $16 \%$.

Em relação às formações continuadas, imperam as respostas sobre atividades desenvolvidas pelas secretarias municipais de educação. Em Salvador, 65\% dos(as) professores(as) dizem ter participado de alguma atividade de formação promovida pela SEMED. Em Jacobina, também se registra um quantitativo expressivo, pois $60 \%$ dos(as) professores(as) dizem ter realizado alguma atividade de formação via Secretaria da Educação. Esse dado pode ser explicado pelo número elevado de projetos e propostas de formação que as secretarias municipais têm desenvolvido, com vistas a auxiliar os(as) professores(as) na atuação profissional. Além disso, os cursos ofertados pelas duas redes são elementos basilares para a garantia do processo de promoção na carreira, o que faz com que se eleve o número de docentes participantes a partir de cursos com carga horária mínima de 80 horas. É possível observar que esta ênfase nos cursos de formação continuada realizados pelas secretarias municipais possui uma relação direta com a Rede Nacional de Formação Continuada de professores da Educação Básica, ${ }^{7}$ em que cursos sobre Pró-letramento,

7 A Rede Nacional de Formação Continuada de Professores da Educação Básica foi criada em 2004, pelo Ministério de Educação e Cultura, com metas de "articular a pesquisa, a produção acadêmica à formação dos educadores, processo que não se completa por ocasião do término de seus estudos em cursos superiores" (BRASIL, 2004, p. 3). 
Gestar e programas específicos das secretarias municipais de educação, como Nossa Rede, em Salvador, constituíram a centralidade das formações.

Identificamos, ainda, um considerável número de professores(as) que afirmam ter realizado eventos e cursos com investimento próprio. São 46\% em Salvador. Esse dado pode se justificar pela oferta de cursos e formações outras que acontece em Salvador na rede privada, em que os(as) professores(as) precisam custear a sua formação. Esse número é menor em Jacobina, perfazendo apenas 19\% dos(as) respondentes. Em Jacobina registram-se poucas empresas e instituições que ofertam cursos na rede privada, não possibilitando aos(às) professores(as) se inserirem nesse tipo de formação.

Fazendo uma espécie de interseção entre os eventos de formação de que participaram os(as) professores(as) com as temáticas abordadas nos percursos formativos, buscamos saber em quais atividades de formação continuada as questões de diversidade foram abordadas. Ressalte-se que essa foi, também, uma questão que permitiu que o(a) professor(a) marcasse mais de uma possibilidade, caso ele(ela) tivesse realizado mais de uma atividade ofertadas pela escola, secretaria municipal de educação ou com recursos próprios, nos quais as temáticas tivessem aparecido. Em 27\% das respostas dadas pelos(as) professores(as) de Salvador, não houve nenhuma temática que abordasse algumas das diversidades descritas.

Em Jacobina, segundo as respostas dos(as) participantes, as formações ofertadas pela secretaria municipal de educação que abordam questões da diversidade perfazem um total de $31 \%$. Em atividades realizadas pela própria escola, 23\% tratam destas questões, e nos cursos ofertados em outros espaços encontramos um percentual de $21 \%$. Nos cursos em que o(a) professor(a) fez por conta própria, apenas 12\% abordam essas temáticas. Neste último caso, a explicação pode ser analisada pela própria escolha do(a) professor(a) de não buscar cursos que estejam diretamente ligados às discussões da diversidade. No entanto, na escola e na secretaria municipal da educação, a tendência é de inserir as questões da diversidade na formação, buscando subsidiar os(as) docentes para a atuação profissional em contextos de diversidade.

Nos municípios baianos envolvidos com a pesquisa, é baixa a relação de temas voltados para a diversidade nos cursos e formação continuada realizados pelos(as) professores(as). Em Salvador, 30,4\% responderam que participaram de cursos voltados para temáticas mais gerais sobre a diversidade (concepções; Lei 10.639/2003, temas da Educação de Jovens e Adultos), enquanto em Jacobina foram $36,8 \%$ dos(as) respondentes. As questões mais específicas da diversidade, voltadas para os estudantes, foram tratadas apenas com os cursos voltados para a Educação Especial; destes, em Salvador houve 19,5\% dos(as) docentes participantes, e em Jacobina, 33,3\%. Os dados revelaram que houve uma entrada ainda tímida das temáticas da diversidade nos cursos oferecidos pelas Secretarias de Educação, revelando a necessidade de oportunizar reflexões sobre o trabalho docente com a diversidade. Em relação à formação continuada dos(as) professores(as), o Plano Nacional de Educação (BRASIL, 2014) prevê que deve ser garantido a todos(as) os(as) profissionais, a partir de sua área de atuação, incentivo para que os(as) professores(as) realizem cursos voltados para o trabalho com a diversidade.

Além das formações desenvolvidas pelas Secretarias, os(as) professores(as) participam de formações dadas pelas universidades através de congressos, encontros, entre outros. Esse tipo de formação tem sido uma forma de os(as) professores(as), em ambos os municípios, lograrem formações em que a temática da diversidade também esteja presente. Entretanto, o que impede os(as) professores(as) da Educação Básica de investirem nesse tipo de formação é a condição de trabalho, uma vez que a maioria dos(as) professores(as) trabalha 40 horas, em 
dois turnos na unidade educacional. Além disso, o fato de não poder suspender aulas e nem ter professores(as) para garantir a substituição do(a) docente que se ausenta para participação em eventos dessa natureza tem-se constituído como impedimento para que esse tipo de formação continuada gere resultados significativos no contexto das práticas educativas.

Ainda que a formação continuada tenha sido vivenciada em um período em que as políticas da diversidade estavam no cerne da discussão/ implementação no país, percebemos na pesquisa que os(as) professores(as) apontaram pouca inserção em cursos que abordaram esta temática. A preocupação dos(as) professores(as) e das próprias secretarias municipais de educação estiveram voltadas para questões mais diretamente ligadas aos processos gerais de aprendizagem dos(as) estudantes e com a inserção das tecnologias para que o(a) docente pudesse lidar com as ferramentas necessárias para este contexto (temáticas presentes nos cursos de formação continuada com maior incidência de participação dos(as) docentes nos dois municípios). Isto não significa que as temáticas sobre a diversidade foram invisibilizadas nos municípios, entretanto não ganharam tamanho destaque que o cenário político educacional das últimas duas décadas apontou como possibilidade de enfretamento das desigualdades sociais presentes no universo da escola.

\section{Algumas considerações}

Os dados analisados revelaram que tanto a formação inicial como a continuada são fundantes para que os(as) professores(as) possam compreender e lidar com as questões da diversidade no seu fazer educativo. Há, no entanto, um destaque para a formação continuada, lócus em que se visibiliza a temática em torno das questões da diversidade, que emergem tanto da própria formação que os(as) professores(as) realizaram, como da atuação destes(as) na profissão docente.
A pesquisa mostrou, ainda, os impactos da formação para o trabalho com a diversidade na Educação Básica, que como apontam os resultados da pesquisa, mantém direta relação com as políticas voltadas para a formação de professores(as) em contextos de diversidade, as quais se intensificaram a partir da ação da SECAD/SECADI, que dentre outras ações, buscou implementar o desenvolvimento inclusivo dos sistemas de ensino, voltados à valorização política da diversidade, com vistas a garantir a promoção da educação inclusiva, dos direitos humanos e da sustentabilidade socioambiental, visando à efetivação de políticas públicas transversais e intersetoriais. Assim, considerando que a formação lograda pelos participantes do estudo está compreendida, sobretudo, por um período em que as questões da diversidade estavam em pauta nas políticas de formação de professores(as), o resultado aponta para uma valorização e reconhecimento da diversidade como elemento basilar que deve estar presente tanto nos cursos de formação inicial como continuada.

É preciso considerar que as Diretrizes Curriculares Nacionais para a Formação Inicial e Continuada dos Profissionais da Educação Básica, conforme o Parecer CNE/CP no 2, de 09 de junho de 2015 (BRASIL, 2015), trouxe para cena a necessidade de formar os(as) professores(as) em alinhamento com as práticas educativas desenvolvidas no cotidiano escolar. Isso justificou a dimensão de ampliar para 800 horas, conforme tal resolução, a carga horária destinada a práticas e estágios supervisionados. Dentre os objetivos de tal ampliação está a ideia de que a formação deve contemplar as questões que emergem da própria profissão, dentre as quais o trabalho com a diversidade se insurge como um modo de compreender como $o(a)$ professor(a) desenvolve as suas práticas.

No que tange a formação inicial, vimos que os(as) professores(as) possuem formação em licenciatura, com a maioria formada por instituições públicas. São professores(as) que avaliam positivamente a formação que obtiveram 
para o desenvolvimento da profissão docente. Assim, a pesquisa evidenciou que a formação inicial é fundante para que o(a) professor(a) possa atuar na profissão, entendo que é nela que as aprendizagens para atuação docente se iniciam, mas que continuam nos processos de formação continuada que realizam tais participantes.

Com relação à formação continuada, a pesquisa evidenciou que os(as) professores(as) buscaram esse tipo de formação por duas razões centrais: pela possibilidade de progredirem na carreira, uma vez que as formações são pontuadas para garantia de elevação do soldo; e pela necessidade de buscar desenvolver novas aprendizagens em torno das atividades que realizam nas escolas. A pós-graduação lato sensu destaca-se como a mais procurada pelos(as) docentes. A pós-graduação stricto sensu está presente, mas em menor percentual. A razão para isso pode ser a baixa oferta dessa modalidade de curso no Estado, sobretudo em Jacobina, que conta apenas com um programa de mestrado profissional na área de educação.

Ao tensionarmos os resultados da pesquisa com o cenário atual sobre as políticas de formação dos(as) professores(as), concluímos que há um silenciamento de políticas que valorizem o trabalho da diversidade em sala de aula. Isso já se inicia com o desmonte da SECADI e com a homologação da Base Nacional Comum Curricular (BNCC), que invisibiliza a questão da diversidade, não a reconhecendo como central no processo de formação dos(as) professores(as). A atual conjuntura política do país é extremamente preocupante, na medida em que além das questões da diversidade serem tratadas como não pertinentes ao trabalho do(a) professor(a), gera-se um ataque à figura do(a) docente, cuja autonomia e condições de trabalho vão se tornando cada vez mais ameaçadas. No bojo dessas questões, ameaçam-se e desmontam-se as políticas de formação de professores(as), sobretudo no que tange aos contextos em que a diversidade pese como uma dimensão relevante na profissão docente.

\section{REFERÊNCIAS}

BRASIL. Ministério da Educação. Decreto-Lei no 8.530, de 02 de janeiro de 1946. Lei Orgânica do Ensino Normal. Rio de Janeiro, 1946. Disponível em: https://www2.camara.leg.br/legin/fed/ declei/1940-1949/decreto-lei-8530-2-janeiro1946-458443-publicacaooriginal-1-pe.html. Acesso em: 10 dez. 2019.

BRASIL. Câmara dos Deputados. Lei no 5.692, de 11 de agosto de 1971. Fixa Diretrizes e Bases para o ensino de $1^{\circ}$ e $2^{\circ}$ graus, e dá outras providências. Brasília, DF, 1971. Disponível em: https://www2. camara.leg.br/legin/fed/lei/1970-1979/lei-569211-agosto-1971-357752-publicacaooriginal-1-pl. html. Acesso em: 04 dez. 2019.

BRASIL. Presidência da República. Casa Civil. Constituição da República Federativa do Brasil de 1988. Brasília, DF, 1988. Disponível em: http:// www.planalto.gov.br/ccivil_03/constituicao/ constituicaocompilado.htm. Acesso em: $04 \mathrm{dez}$. 2019.

BRASIL. Ministério da Educação e Cultura. Plano decenal de educação para todos. Brasília, DF, 1993.

BRASIL. Lei de Diretrizes e Bases da Educação Nacional: Lei no 9.394, de 20 de dezembro de 1996, que estabelece as diretrizes e bases da educação nacional. 7. ed. Brasília, DF: Edições Câmara, 2012. BRASIL. Ministério da Educação. Secretaria de Educação Fundamental. Parâmetros curriculares nacionais: introdução aos parâmetros curriculares nacionais. Brasília, DF: Ministério da Educação/ Secretaria de Educação Fundamental, 1997. Disponível em: http://portal.mec.gov.br/seb/ arquivos/pdf/livro01.pdf>. Acesso em: dez. 2019.

BRASIL. Ministério Extraordinário de Política Fundiária. PRONERA - Manual de Operações 1998. Brasília, DF, 1998.

BRASIL. Conselho Nacional de Educação. Câmara de Educação Básica. Resolução CNE/CEB no 01/2002, de 03 de abril de 2002. Institui Diretrizes Operacionais para Educação Básica nas Escolas do Campo. Brasília, DF, 2002. Disponível em: http://portal.mec.gov.br/index.php?option=com docman \&view $=$ download \&alias $=13800$ rceb001-02-pdf\&category_slug=agosto-2013pdf\&Itemid=30192. Acesso em: nov. 2019.

BRASIL. Presidência da República. Casa Civil. Lei no 10.639, de 9 de janeiro de 2003. Altera a Lei ${ }^{\circ}$ 
9.394, de 20 de dezembro de 1996, que estabelece as diretrizes e bases da educação nacional, para incluir no currículo oficial da Rede de Ensino a obrigatoriedade da temática "História e Cultura Afro-Brasileira", e dá outras providências. Brasília, DF, 2003. Disponível em: http://www.planalto. gov.br/ccivil_03/leis/2003/110.639.htm. Acesso em: 10 dez. 2019.

BRASIL. Ministério da Educação. Decreto no 5.159, de 28 de julho de 2004. Aprova a Estrutura Regimental e o Quadro Demonstrativo dos Cargos em Comissão e das Funções Gratificadas do Ministério da Educação, e dá outras providências. Brasília, DF, 2004. Disponível em: http://portal. mec.gov.br/arquivos/pdf/d5159.pdf. Acesso em: 04 dez. 2019.

BRASIL. Ministério da Educação. Rede Nacional de Formação Continuada de Professores. Brasília, DF, 2004. Disponível em: http://portal.mec.gov. $\mathrm{br} /$ rede-nacional-de-formacao-continuada-deprofessores. Acesso em: 05 dez. 2019.

BRASIL. Presidência da República. Casa Civil. Decreto no 5.800, de 08 de junho de 2006 . Dispõe sobre o Sistema Universidade Aberta do Brasil - UAB. Brasília, DF, 2006. Disponível em: http://www.planalto.gov.br/ccivil_03/_Ato20042006/2006/Decreto/D5800.htm. Acesso em: nov. 2019.

BRASIL. Ministério da Educação. Secretaria de Educação Continuada, Alfabetização, Diversidade e Inclusão. Programa de Apoio à Formação Superior em Licenciatura em Educação do Campo (Procampo). Apresentação. Brasília, DF, 2007. Disponível em: http://portal.mec.gov.br/index. php?option=com_content $\&$ view $=$ article $\& i d=123$ 95:apresenta. Acesso em: nov. 2019.

BRASIL. Presidência da República. Casa Civil. Decreto no 6.755, de janeiro de 2009. Institui a Política Nacional de Formação de Profissionais do Magistério da Educação Básica, disciplina a atuação da Coordenação de Aperfeiçoamento de Pessoal de Nível Superior CAPES no fomento a programas de formação inicial e continuada, e dá outras providências. Brasília, DF, 2009a. Disponível em: https://www.capes.gov.br/images/stories/ download/legislacao/Decreto-6755-2009.pdf. Acesso em: nov. 2019.

BRASIL. Ministério da Educação. Portaria Normativa no 09, de 30 de junho de 2009. Institui o Plano Nacional de Formação dos Professores da Educação Básica no âmbito do Ministério da
Educação. Brasília, DF, 2009b. Disponível em: http://portal.mec.gov.br/dmdocuments/port normt_09_300609.pdf. Acesso em: nov. 2019.

BRASIL. Conselho Nacional de Educação. Câmara Básica de Educação. Resolução CNE/CEB no 04, de 13 de julho de 2010. Define Diretrizes Curriculares Nacionais Gerais para a Educação Básica. Brasília, DF, 2010. Disponível em: http:// portal.mec.gov.br/dmdocuments/rceb004_10.pdf. Acesso em: 04 dez. 2019.

BRASIL. Presidência da República. Casa Civil. Decreto no $\mathbf{7 . 4 8 0}$, de 16 de maio de 2011. Aprova a estrutura regimental e o quadro demonstrativo de dos cargos em comissão do grupo-direção e assessoramento superiores - DAS e das funções gratificadas do Ministério da Educação e dispõe sobre remanejamento de cargos em comissão. Brasília, DF, 2011. Disponível em: http://www. planalto.gov.br/ccivil_03/_Ato2011-2014/2011/ Decreto/D7480.htm. Acesso em: nov. 2019.

BRASIL. Ministério da Educação. Secretaria de Educação Continuada, Alfabetização, Diversidade e Inclusão.Programa Nacional de Educação do Campo PRONACAMPO. Brasília, DF, 2013. Disponível em: http://portal.mec.gov.br/index.php?option=com docman \&view =download \&alias $=13214$ documento-orientador-do-pronacampopdf\&Itemid=30192. Acesso em: dez. 2019.

BRASIL. Presidência da República. Casa Civil. Lei no 13.005, de 25 de junho de 2014. Aprova o Plano Nacional de Educação - PNE e dá outras providências. Brasília, DF, 2014. Disponível em: http://www.planalto.gov.br/ccivil03/ato20112014/2014/lei/l13005.htm. Acesso em: dez. 2019.

BRASIL. Conselho Nacional de Educação. Parecer CNE/CP no 2/2015, de 09 de junho de 2015. Diretrizes Curriculares Nacionais para a formação inicial em nível superior (cursos de licenciatura, cursos de formação pedagógica para graduados e cursos de segunda licenciatura) e para a formação continuada. Brasília, DF, Diário Oficial [da] República Federativa do Brasil, seção 1, p. 13, 25 jun., 2015.

BRASIL. Conselho Nacional de Educação. Conselho Pleno. Resolução CNE/CP no 02/2015, de 1ำ de julho de 2015. Define as Diretrizes Curriculares Nacionais para a formação inicial em nível superior (cursos de licenciatura, cursos de formação pedagógica para graduados e cursos de segunda licenciatura) e para a formação continuada. Brasília, DF, 2015. Disponível em: http://portal.mec.gov.br/ 
docman/agosto-2017-pdf/70431-res-cne-cp-00203072015-pdf/file. Acesso em: 10 dez. 2019.

BRASIL. Ministério da Educação. Secretaria da Educação Básica. Base Nacional Comum Curricular. Brasília, DF, 2017. Disponível em: http:// basenacionalcomum.mec.gov.br/\#/site/inicio. Acesso em: dez. 2019.

CARREIRA, Denise. Igualdade e diferenças nas políticas educacionais: a agenda da diversidade nos governos Lula e Dilma. São Paulo: Ação Educativa, 2017.

CANDAU, Vera Maria (org.). Didática crítica intercultural: aproximações. Petrópolis, RJ: Vozes, 2013.

CANDAU, Vera Marai Ferrão. Diferenças, desigualdades e educação escolar: desafios da perspectiva intercultural. In: RIOS, Jane Adriana Vasconcelos Pacheco Rios (org.). Diferenças e desigualdades no cotidiano escolar da Educação Básica. Campinas, SP: Mercado das Letras, 2017. p. 23-56.

DESLANDES, Keila. Formação de professores e direitos humanos: construindo escolas promotoras da igualdade. Belo Horizonte: Autêntica, 2015. (Coleção Cadernos de Diversidade).

FLEURY, Reinaldo Matias. Educação intercultural: a construção da identidade e da diferença nos movimentos sociais. Revista Perspectiva, Florianópolis, v. 20, n. 2, p. 405-423, jul./dez. 2002.

FREITAS, Helena Costa Lopes. Formação inicial e continuada: a prioridade ainda postergada. $I n$ : OLIVEIRA, Dalila Andrade; VIEIRA, Lívia Fraga (org.). Trabalho na Educação Básica: a condição docente em sete estados brasileiros. Belo Horizonte: Fino Traço, 2012. p. 91-129.

GOMES, Nilma Lino. Políticas públicas para a diversidade. Revista Sapere Aude, Belo Horizontes, v. 8, n. 15, p. 7-22, jan./jun. 2017a.

GOMES, Nilma Lino. 0 movimento negro educador. Petrópolis, RJ: Vozes, 2017b.

IVENICKI, Ana. Políticas educacionais e diversidade na escola: desafios da/na contemporaneidade. In: RIOS, Jane Adriana Vasconcelos Pacheco Rios (org.). Políticas, práticas e formação na educação básica. Salvador: EDUFBA, 2015. p. 13-22.

IVENICKI, Ana. Multiculturalismo e formação de professores: dimensões, possibilidades e desafios na contemporaneidade. Ensaio: Avaliação e políticas públicas em Educação, Rio de Janeiro, v. 26, n. 100, p. 1151-1167, jul./set. 2018.

MCLAREN, Peter. Multiculturalismo crítico. Tradução de Bedel Orofino Schaefe. São Paulo: Cortez, 2000.

NÓVOA, António. 0 regresso dos professores. Pinhais, PR: Melo, 2011.

NOVOA, António. Firmar a posição como professor, afirmar a profissão docente. Cadernos de Pesquisa, v. 47, n. 166, p. 1106-1133, 2017. Disponível em: http://dx.doi.org/10.1590/198053144843. Acesso em: 10 nov. 2019.

ORGANIZAÇÃO DAS NAÇÕES UNIDAS. III Conferência Mundial contra o Racismo, a Discriminação Racial, a Xenofobia e Formas Correlatas de Intolerância Conferência de Durban. Durban, África do Sul, 2001. Disponível em: http://www.unfpa.org.br/Arquivos/ declaracao_durban.pdf. Acesso em: dez 2019.

RIOS, Jane Adriana Vasconcelos. Modos de habitar a profissão docente na educação básica. Texto apresentado na Banca de Promoção Docente para Professor Titular Pleno. Salvador: UNEB, 2019. No prelo.

RIOS, Jane Adriana Vasconcelos Pacheco (coord.). Profissão Docente na Educação Básica da Bahia. Salvador: Universidade do Estado da Bahia, 2016.

SALVADOR. Leis Municipais. Lei complementar no 34, de 09 de junho de 2003. Altera, acrescenta e revoga dispositivos da lei complementar $n$ 이 1/91 que "institui o regime jurídico único dos servidores públicos do município de salvador", e suas alterações posteriores e dá outras providências. Disponível em: https://leismunicipais.com.br/estatuto-doservidor-funcionario-publico-salvador-ba. Acesso em: 01 nov. 2019.

SURVEY. 2017. Disponível em: https://survey.com. br. Acesso em: 11 nov. 2019.

WASH,Catherine. Interculturalidade crítica e educação intercultural. In: SEMINÁRIO INTERCULTURALIDAD Y EDUCACIÓN INTERCULTURAL, 2009, La Paz. Anais [...]. La Paz: Instituto Internacional de Integración del Convenio Andres Bello, 2009.

Recebido em: 27/12/2019 Aprovado em: 13/02/2020 